\title{
INTERNET ACCESS AND USAGE IN IMPROVING STUDENTS' SELF-DIRECTED LEARNING IN INDONESIA OPEN UNIVERSITY
}

\author{
Djoko RAHARDJO \\ Faculty of Social and Politiacl Sciences \\ Universitas Terbuka, Indonesia \\ Prof. Dr. SUMARDJO \\ Faculty of Human Ecology \\ Bogor Agricultural University, Indonesia \\ Dr. Djuara P. LUBIS \\ Faculty of Human Ecology \\ Bogor Agricultural University, Indonesia \\ Dr. Sri HARIJATI \\ Faculty of Mathematics and Sciences \\ Universitas Terbuka, Indonesia
}

\section{ABSTRACT}

Internet is well known nowadays, however higher distance education students who live in remote rural areas still have not been able to take advantages of this medium optimally for their learning process. For accessing the internet the students have to be available with the minimum prerequisites: the existence of adequate devices and the sufficient capabilities. For education purposes, the students use the internet to meet their information and fulfill learning needs, facilitate interpersonal communications, and provide groups of discussion, as well as to be connected with friends in social media. This study aims to analyze the relationship between internet access and usage in improving students' self-directed learning which is using structural equation model method. The survey is conducted in seven districts in Surakarta Regional Office of Indonesia Open University with a sample size of 320 respondents. The result shows that the internet usage is still low due to limited internet facilities that affect the knowledge and willingness of students to access the internet. The strategy in improving student internet usage is applying social media as guidance that can be accessed through cellular phones.

Keywords: Internet access, internet usage, distance education, self-directed learning

\section{INTRODUCTION}

Internet is growth in popularity as learning media in higher distance education, unfortunately students in some rural areas are still not utilizing the internet to fulfill their need. Web-based distance education application has become increasingly playing an important role in the development of students learning, however it need some requirements to access the internet. To access it, they have to provide themselves, not only with the availability of devices, but also with the access capability.

The use of internet in higher distance education particularly emphasizes on meeting the needs of information, interactive communications between educators and learners in the learning process, forums for students to discuss both teaching materials and other 
academic administrations, as well as social communications which more open among students who are used as a venue for private disclosure or the interests of their learning processes. This is in line with Park in Dogruer et al. (2011) which stated that the function of the internet in education, among others, as (1) storing the information, (2) means of communication without bounds, (3) an interactive online learning. While Gaytan described in Stanciu and Inca (2014) confirmed that there are several levels in the use of the internet, namely, (1) gathering information, (2) sharing information with friends who have the same interest, (3) working on the internet as part which has been planned, (4) studying according to the curriculum that has been prepared by the tutor to be done through the help of it, and (5) designing activities which apply learning independently.

Some researches have been carried out in order to identify and to solve the problem of access and use of internet. For example, Rye and Zubaidah (2008) focused on the problem of accessing the internet at graduate students of Pangkal Pinang Regional Office of Indonesia Open University (Universitas Terbuka/UT) in Bangka Belitung Islands which concluded that student adversity not only on the unavailability of the means but also the problem of unfamiliarity in the internet use. This would be a challenge for students since the absence of other appropriate means to support their learning process.

Daulay (2008), which examined the interaction of students in the Online Communication Forum at the UT's website, identified that the highest rating of communication was personal interactions, and the second rating was problems with tutorials and other administrative matters. The conclusion of the study stated that the biggest obstacle of the students was the lack of communication. Omotayo (2006) conducted a survey of internet use among undergraduates. The results showed that internet use is quite high, especially in internet café. Internet usage does not affect the use of the library. The common problem faced by students is the weak signal from the server and cost issues. Chen and Fu (2009) studied the association between internet use and academic achievement of the high school students in northern Taiwan. The findings confirmed that the search information through online help improve test scores. While the internet which was used in socializing, playing and accessing through internet cafes lowered the performance of their exams. Peou et.al. (2011) observed the relationship of the use and attitudes towards the internet, and the academic utilizing in Cambodia. Use of the internet for academic purposes was still rare among the students. It concluded that main reason was technology adoption costs. All the examples above, however, they were inadequately discussing on the students' attitudes in the access and use of the internet, i.e. internet knowledge, willingness, and the ability to operate the devices.

This research paper presents a survey on students' internet access behavior (IAB) and internet usage (IU) especially their university's website. On the basis of this investigation, it then describes how to improve students self-directed learning (SDL) index. The students who have the ability of SDL becomes importance concept in distance education (Moore and Kearsily, 2012). In online learning, SDL constitutes of the effect of communication process. Index of SDL according to Williamson (2007) can be described in five dimensions of learning, i.e. awareness, learning strategies, learning activities, evaluation, and interpersonal skill. The success of the students in learning processes can be identified by these dimensions.

Departing from the above description, this research purposes can be formulated as follows:

To analyze the relationship between IAB, IU, and SDL?

To formulate a strategy that can be used to improve student SDL index?

\section{METHOD}

\section{Population and Sample}

The population of the study included regular undergraduate students who registered the semester exams in the second academic year of 2013 in Surakarta Regional Office of 
Universitas Terbuka, Indonesia. The random sample was obtained in research sites. The research sites were seven regencies of Surakarta namely Boyolali, Klaten, Karanganyar, Sragen, Sukoharjo, Surakarta, and Wonogiri. According to Kline (2011) that "typical" sample size in studies where structural equation model (SEM) is used is about 200 cases and the same as Hoyle (1995) that stated as "practically reasonable sample size". While Bentler and Chou (1987) suggested the ratio sample size to number of free parameters may be able to go as low as 5:1. Three hundred twenty students ( 320 samples) responded to a questionnaire assessing their behavior related to the internet in the process of learning.

\section{Instrument}

The survey on Internet Access and Usage in improving Self-Directed Learning was based conceptually on the eleven factors. Specific questions were developed to measure selfdirected learning rate which was adopted from Williamson (2007). They were awareness, strategy of learning, activity of learning, evaluation of learning, and interpersonal skill.

Internet access consisted of three main factors, i.e. cognitive, affective, and conative aspect which each of them have three dimensions of questions: using, searching and communicating. The Internet Usage contained three factors, i.e. learning, fulfilling information need, and communicating. Each of them consists of 5 questions. While the environment factor was composed of three factor i.e. availability of internet, social support, and environmental barriers. Face validity of the questions was established by three expert reviewers.

\section{Procedure}

After obtaining approval from the university, survey were conducted. The data collected when the students came to the classroom tutorial (face to face tutorial) places. Before data analysis carried out, the research instrument was examined to get its validity and reliability. These result of the test indicated that the instrument used were sufficiently valid and reliable; with each indicator had a count $r>r$-table $(0.1946)$ and with Cronbach alpha values $=0.919$.

\section{Data Analysis}

In order to get the map of relationships among the variables, SEM method was applied using AMOS 22. Because the result of multivariate test on the variable was non-normally distributed, bootstrapping method was applied, and resample was set to 500 . The final result of model showed that Bollen-Stine bootstrap $\mathrm{p}=0.112$, it meant that the model had a good fit.

\section{RESULTS AND DISCUSSION}

\section{Account and Access Equipment Ownership}

From the analyzing data, it found generally that students owned equipment sufficient enough for them to access the internet, and it was only $6.9 \%$ of the students who do not have access to this equipment. However, it did not reduce the spirit of challenge them to access the internet in fact that half of the students who do not have the equipment have internet accounts (Table 1). To access the internet, they utilized internet café or internet available in the workplace. One fifth (21.3\%) of the number of students did not have an account, although most have internet access equipments. This means that some students were not accustomed to communicating via the internet.

Table: 1

Number of students according to ownership of internet accounts and access equipments

\begin{tabular}{lrrrrrr}
\hline \multirow{2}{*}{$\begin{array}{l}\text { Access Equipment } \\
\text { Ownership }\end{array}$} & $\begin{array}{c}\text { No internet } \\
\text { account }\end{array}$ & \multicolumn{1}{c}{ Email } & \multicolumn{1}{c}{$\begin{array}{c}\text { Email } \\
\text { +Facebook }\end{array}$} & $\begin{array}{c}\text { Email+Facebook } \\
\text { +Twitter }\end{array}$ & \multicolumn{1}{c}{ Total } & $(\%)$ \\
\hline No equipment & 10 & 8 & 3 & 1 & $\mathbf{2 2}$ & $(6.9)$ \\
Cellular phone & 39 & 66 & 38 & 12 & 155 & $(48.4)$ \\
PC+Tablet+Laptop & 5 & 12 & 18 & 2 & 37 & $(11.6)$ \\
All kind of devices & 14 & 41 & 36 & 21 & 106 & $(33.1)$ \\
\hline Total & 68 & 127 & 95 & 36 & 320 & $(100.0)$ \\
$(\%)$ & $(21.3)$ & $(39.7)$ & $(29.7)$ & $(11.3)$ & $(100)$ & \\
\hline
\end{tabular}




\section{Variable Index: Environmental Factors, Internet Access, and Internet Usage}

The capability of students to access the internet was quite good, the students' knowledge and willingness to access these media was high, the ability of the student to access the internet, however, was still in a medium rank (Table 2). Environmental factors were generally considered to be high with low resistance/barriers. It discovered that students' communication with other people using the internet rather low, while the level of the students to exploit the information in the university website was in a medium level. It can be concluded that environmental factors were sufficient to support height student access level, but it could not maintain the level of internet usage.

Table: 2

Variables and Score Values: Environment factors, Internet Access Behavior, Internet

\begin{tabular}{cc}
\multicolumn{1}{c}{ Usage } & \multicolumn{1}{c}{ Score Value(\%) } \\
\hline Variables & \\
\hline Environmental factors & 57.70 \\
Availability of internet & 68.13 \\
Social supports & 34.65 \\
Environmental Barriers & \\
\hline Internet Access Behavior & 75.28 \\
Cognitive/ knowledge & $\mathbf{8 3 . 1 6}$ \\
Affective/ attitude & 56.49 \\
Conative/ ability & \\
\hline Internet use & 36.09 \\
Information need & 27.60 \\
Learning activity & 28.56 \\
Communication &
\end{tabular}

Level of availability of internet facilities are generally inadequate. These findings are similar to the study reported by Rye and Zubaidah (2008) in the Bangka Belitung Islands. It was thought to relate to the availability of telephone networks in the regions where they lived. Family support was an important element for the advancement of student education. With the support of family, students could be better motivated to learn. Support was generally due to economic problems, given that the costs used to access the internet is not cheap (Omotayo, 2006).

\section{Confirmatory Factor Analysis of Access and Use of Internet, and Environment Factors}

Using bootstrap method in AMOS version 22 and setting to be 500 resample, this analysis generated a model of confirmatory analysis as shown in Figure 1. It found that the model had a negative variance $(\mathrm{eF2}=-69,9)$, so variance value had to be changed into smaller (0.005). It found that there were 3 indicators which had loading factors $<0.5$. These indicators had to be dropped for the next analysis. 


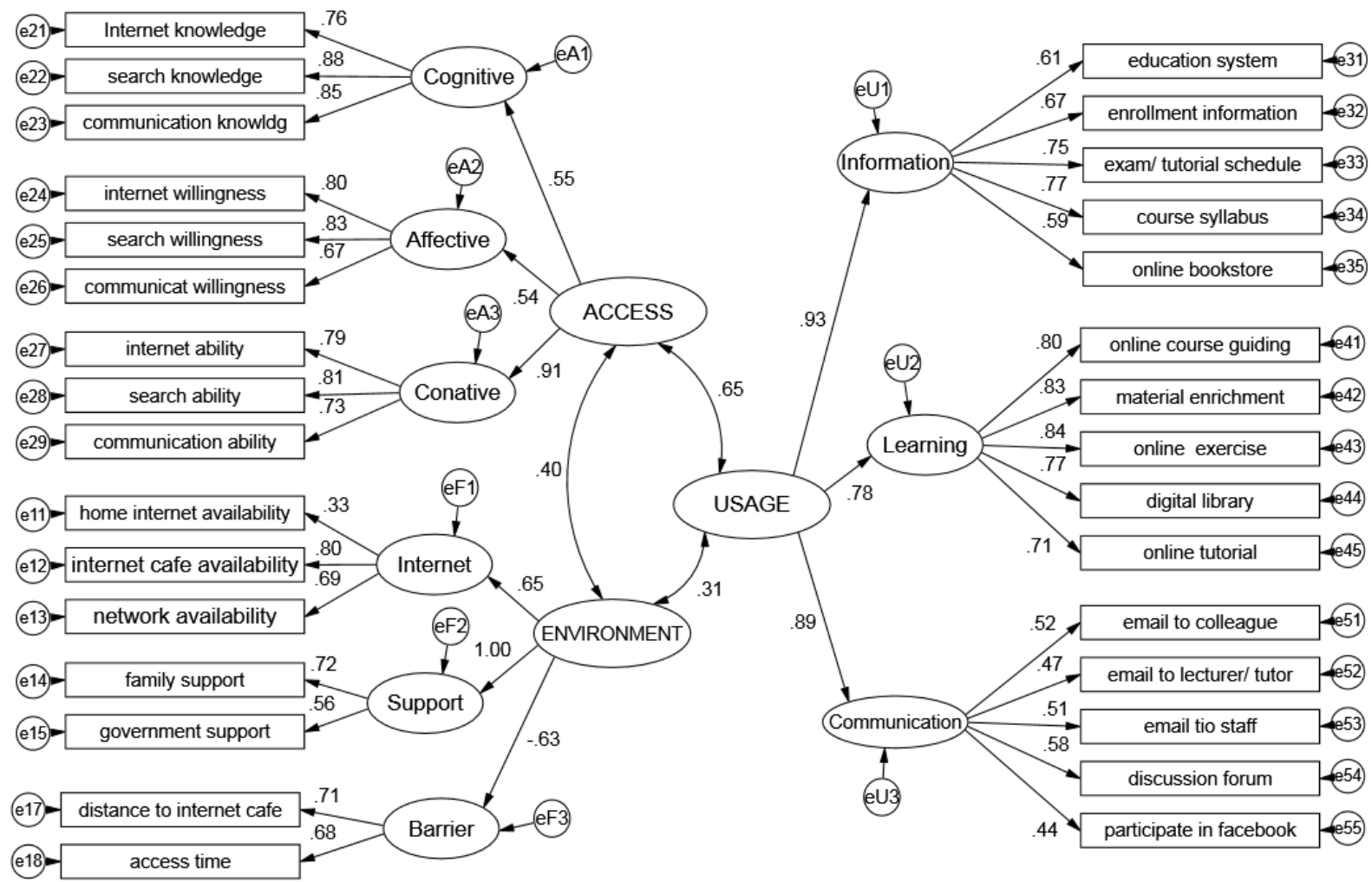

Figure: 1

Confirmatory factor Analysis of Full Model

In order to get a model with valid indicators, some indicators had to be dropped. The final result of confirmatory factor analysis can be seen in Figure 2.

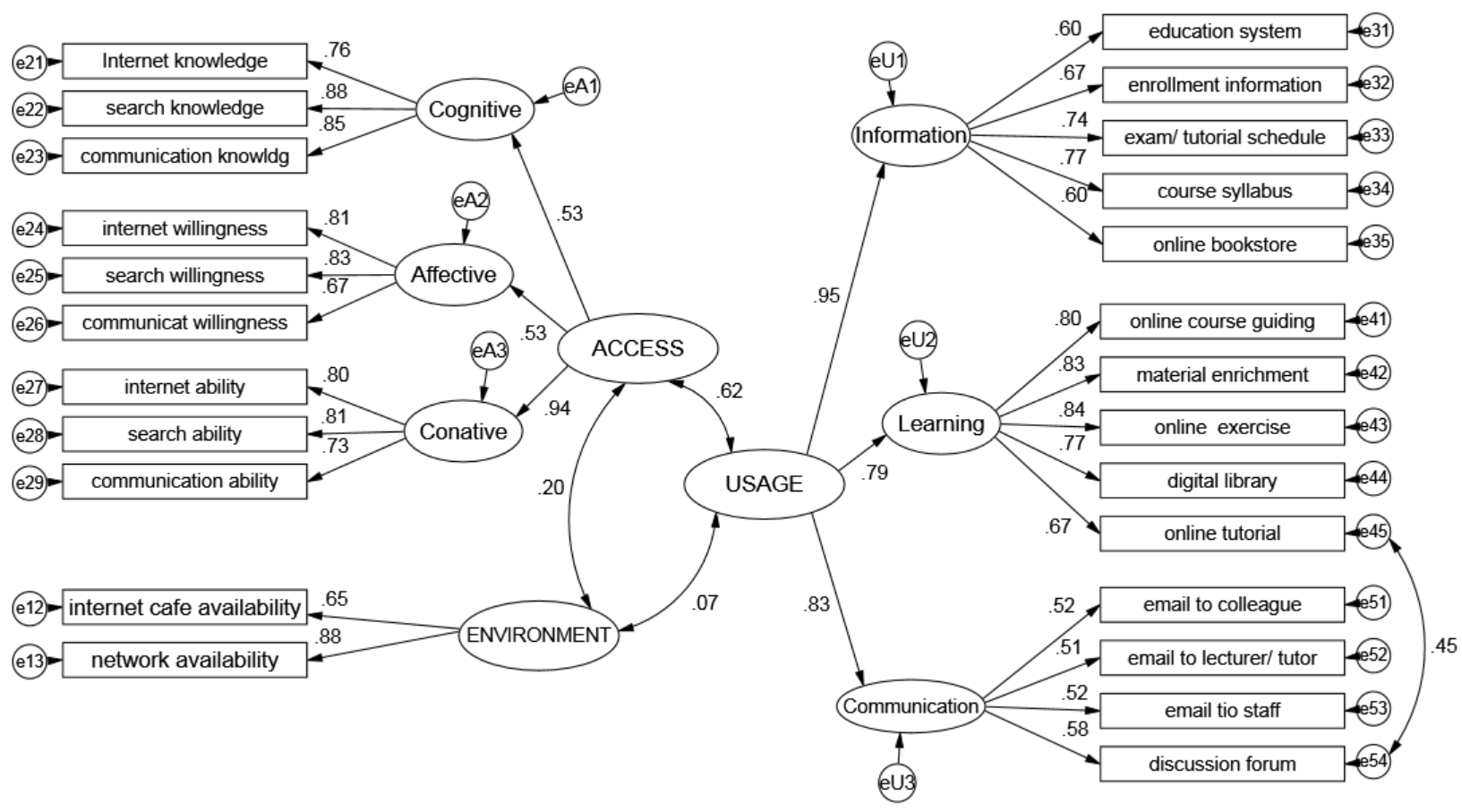

Figure: 2

The Final Result of Confirmatory factor Analysis of Access and Use of Internet 
Model of Access and Use of Internet, and Environment Factors

The final result of model showed that Bollen-Stine bootstrap $\mathrm{p}=\mathbf{0 . 0 5 6}$, it meant that the model had a good fit. As represented in Table 3, the model enjoys good fitness based on the above criteria. RMSEA equals 0.038 which is smaller than 0.8 and the indices GFI, AGFI, and CFI are all greater or near 0.90; therefore the model shows a good fitness and is confirmed.

Table: 3

Goodness of Fit of Access and Usage of Internet Model

\begin{tabular}{ccccccccc}
\hline CMIN & DF & P & CMIN/DF & RMR & GFI & AGFI & CFI & RMSEA \\
\hline 350.73 & 23 & \multirow{2}{*}{0.00} & 1.467 & 33.882 & $\begin{array}{c}0.92 \\
2\end{array}$ & $\begin{array}{c}0.89 \\
3\end{array}$ & $\begin{array}{c}0.96 \\
9\end{array}$ & 0.038 \\
\hline
\end{tabular}

Figure 3 was the final model of Access and Usage of internet. This model illustrates that to improve the rate of the students' internet usage, it needs to maintain environmental factors, however, these factors such as: home internet facilities, family support, environment barriers are personal condition that can not be reached by the institution. This model also reveals that the behavior of access that can be used to improve the use of the internet is the ability to search the information through the internet. Searching in the internet capability is an important aspect to be improved in order to increase their internet use.

Students had enough knowledge to access the internet and they agreed to use internet, but they had inadequately abilities to access it. The students were capable of searching information on the internet. It was the basis for students to develop themselves in the use of the internet. This condition was a pretty good starting point for further development.

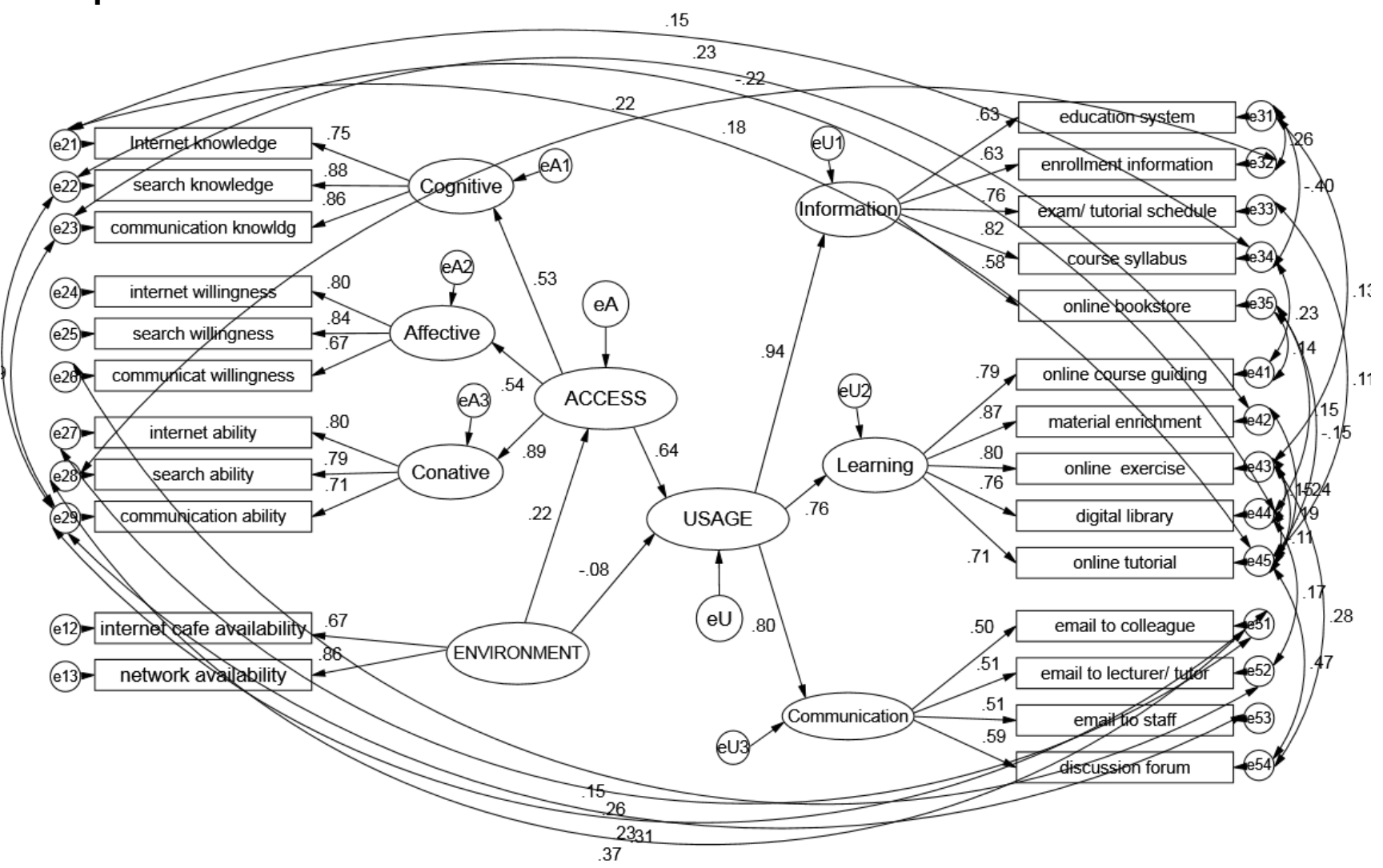

Figure: 3

Final Model of Access and Use of Internet 
Students in the use of the internet for the benefit of the learning process was still deficient. These findings confirmed what has been studied by Peou et.al. (2011) in Cambodia. Online exercise was still underutilized by students, and it was suspected that students preferred to use offline exercises provided in their textbook for lower cost. That the use of online tutorial was at a low level showed that the students were not yet accustomed to taking the advantage of application. It was assumed that student still preferred traditional ways of learning, classroom tutoring.

Students still rarely used email to communicate better with friends, faculty, and academic staff UT. This finding was similar to Daulay (2008) which stated that students were less communicate.

The Relationship among the Internet Access and Use, Self-Directed Learning, and GPA In order to identify the relationship among the internet access and use, self-directed learning, and GPA, the data were correlated using SPSS. It found that students in accessing the internet was positively correlated with the use of the internet and self directed learning, but not positively correlated with GPA. Internet usage correlated with self directed learning but not correlated with GPA, while self directed learning was positively correlated with GPA (Table 4). Therefore any change in internet access behavior and internet usage will affect students' self directed learning. The effect on internet access behavior to GPA was indirectly. It is similar to Chen and Fu (2009) who found that the search through the internet helps improve GPA.

Table: 4

Correlation matrix between Internet access, Internet usage, Self-directed learning, and GPA $(\mathbf{N}=320)$

\begin{tabular}{llcccc}
\hline Variables & $\begin{array}{l}\text { Spearman's } \\
\text { rho }\end{array}$ & $\begin{array}{c}\text { Internet } \\
\text { Access }\end{array}$ & $\begin{array}{c}\text { Internet } \\
\text { usage }\end{array}$ & $\begin{array}{c}\text { Self-Directed } \\
\text { learning }\end{array}$ & GPA \\
\hline Internet access & $\begin{array}{l}\text { Corr. Coef. } \\
\text { Sig. (2- } \\
\text { tailed) }\end{array}$ & 1 & $0.469 * *$ & $0.307 * *$ & 0.040 \\
& $\begin{array}{l}\text { Corr. Coef. } \\
\text { Sig. (2- } \\
\text { tailed) }\end{array}$ & & 0.000 & 0.000 & 0.447 \\
\hline Self-directed learning & $\begin{array}{l}\text { Corr. Coef. } \\
\text { Sig. (2- } \\
\text { tailed) }\end{array}$ & 1 & $0.178 * *$ & 0.010 \\
& $\begin{array}{l}\text { Corr. Coef. } \\
\text { Sig. (2- } \\
\text { tailed) }\end{array}$ & &. & .001 & 0.870 \\
\hline GPA & & & & & $0.135^{*}$ \\
& & & & & 0.015 \\
\hline
\end{tabular}

\section{Strategy to Improve Self Directed Learning}

Importance and Performance Analysis

According to Pike (2004) the importance-performance analysis techniques could be used to assist in decision-making according to priority. Using scatter plot graphic in SPSS, this analysis results a matrix formed by the two axes, namely, the $X$ axis was the score values, while the $Y$ axis was the loading factors. The matrix formed four quadrants, i.e. quadrant-1 and quadrant-2 had a high priority, quadrant-3 and quadrant-4 had a low priority.

In general, internet access behavior was a group of attributes that need to be maintained and receive the highest priority in improvement, while internet usage especially in the aspect of learning was the next priority needs to be increased (Figure 4). 


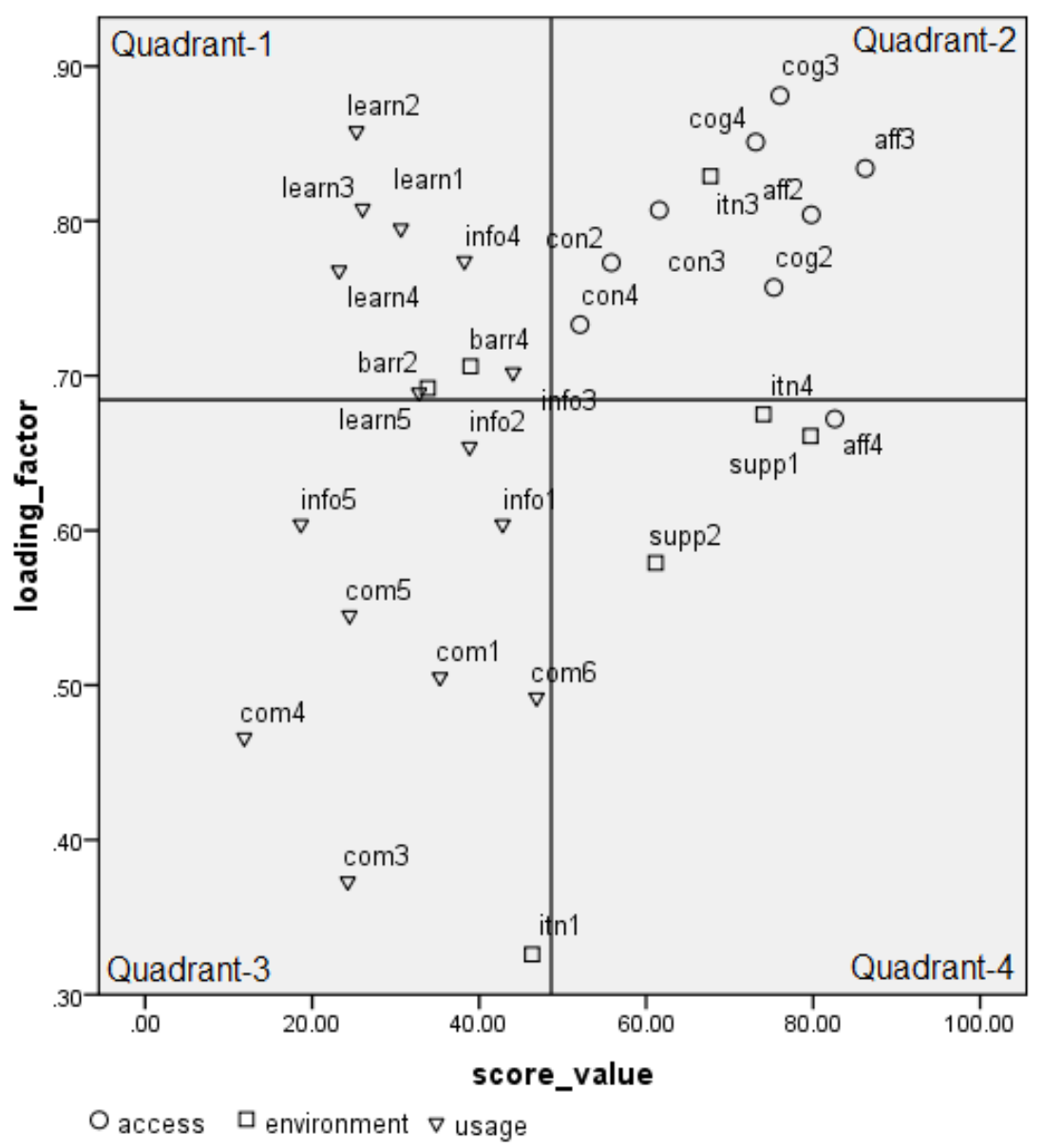

Specification:

itn1 =home internet facility

itn3 = café availability

itn4 = network availability

supp1 $=$ family support

supp2 $=$ government support

barr2 = distance to cafe

barr4 $=$ barrier access time

$\operatorname{cog} 2=$ internet knowledge

$\operatorname{cog} 3=$ searching knowledge

$\operatorname{cog} 4=$ communication knowledge

aff2 = internet access willingness

aff 3 = searching willingness

aff4 $=$ communication willingness

con2 $=$ internet ability

con3 = searching ability

con 4 = communication ability

info1 $=$ education systems

info2 $=$ enrollment information

info3 $=$ exam / tutorials schedule

info 4 = course syllabus

info5 $=$ online bookstore

learn1 $=$ online course guiding

learn2 = enrichment of materials

learn $3=$ online exercise

learn4 $=$ digital library

learn5 $=$ Online tutorial

$\operatorname{com} 1=$ email to colleague

$\operatorname{com} 2=$ email to lecturers

$\operatorname{com} 3=$ email to staff

com4 = discussion forum

$\operatorname{com} 5=$ participate in facebook

Figure: 4

Matrix of Importance Performance Analysis on Indicators

Attributes in first quadrant were generally dominated by the half of the group variable of internet usage. This attributes had a high importance but low in performance. This condition illustrated that these attributes should be encouraged to be improved. Attributes in second quadrant were a group variable of internet access on all aspects, cognitive, affective, and conative. The group had both high importance and performance. This condition described that these attributes should get the first priority for further development. While attributes in quadrant-3 and quadrant-4 were groups of environmental factors and the internet usage. This condition had both low in importance and performance. This exemplified that these attributes were in a low priority.

\section{Strategy to Improve Self- Directed Learning}

By improving access and use of the internet was expected to result in increased students' self-directed learning, which in turn will affect the student achievement index or GPA. Based on the analysis that has been outlined, it can be formulated a strategy in order to improve student self-directed learning.

\section{Increasing Internet Access}

The access devices were tools that must be absolutely available so that students could access the internet. As alternatives, the students could rent these devices at the internet cafes or other ways that could be managed by the students. While UT as the source of information which serves disseminating information through the media should make the absorption rate of information better. To increase it, UT had to pay attention to the facilities covered by the students, cellular phones were generally available. Therefore, the application in accordance with their internet devices should be considered to be developed more comprehensively. 
The ability of searching plays an influential aspect for the improvement of self-directed learning. Searching information capability needs to get serious attention from UT institutions. This capability will allow students to obtain information quickly, as well as select information related to their needs. Regional Offices, who serves as the representative of the university, already provided training on how to access and use of the internet to the students during the first year they enroll UT, however, these capabilities should be developed in more practical.

\section{Improving Internet Usage}

To improve students in using the internet, UT need to do things as follows:

To accomplish the information need is the basic requirement that the student learning process can take place. UT as an institution has prepared a variety of information to meet the needs of students. To improve the internet usage rate, UT as the information source should apply more intensive socialization through meetings in Regional Offices or in student study groups to learn about the features that are available in the Website UT. This way will result increasing of student knowledge in the available information more efficiently.

The internet usage for learning dimension is an important aspect in distance education. UT institutions fully understand that the internet has characteristics best suited to distance education system. The low level of internet usage in the dimension of learning is the consequence of failure devices used by the students that cannot retrieve the information available. Therefore, it needs the development of internet program which is more accessible by cheaper equipment and affordable for students.

Internet usage for the communication needs is also an aspect that is no less important. The low level of the communication resulted in low student motivation to learn. The low of internet use in communication aspect can be fixed by the use of social media (Facebook or Twitter) as an alternative medium. Social media can solve the problem of technological limitations. Too large access charges lead to weaken the response rate of the server computer. Similarly, the addition of a new feature to the system that's already established would increase to the load of the server computer.

\section{CONCLUSIONS}

Based on the results and discussion that has been described can be summarized as follows:

> Low levels of access equipment availability is a major factor for the lack of internet usage among UT students in the remote area. Access equipment owned by students, cellular phones, do not reach adequately the information provided by UT.

$>$ The students' searching capabilities including the aspects of knowledge, willingness, as well as ability, have a positive association with the students in using the internet. The lower capability of students in searching information becomes the one of factors that can determine the weakness of study completion.

$>$ The level of internet usage in searching information and in learning dimensions generally remains at a low level. Since the internet usage has positively correlation with self-directed learning, the very low learning dimension in internet usage will affects the students' self directed learning..

$>$ The strategy which is expected to enhance students' SDL is aimed at strengthening the ability of searching information, increased the use of the internet on aspects of learning by using less expensive access equipment, and the development of the use of social media as a second media to cope with technological problems. 


\section{RECOMMENDATIONS}

Based on the results and conclusions of research can be put forward the following suggestions:

$>$ In order to solved the problem of the low rate of internet usage with the condition of limited access devices, UT should develop an extension application that aims at expanding internet access and it should be strengthened to the devices which have been already owned by most of the students. Most devices in Indonesia from the cheapest to the most expensive ones (cellular phones or tablets) use "android" application, for that reason UT should take notice to this application.

$>$ In order to increase self-directed learning it is necessary to strengthen the capability of students in searching the internet since SDL has positively correlation with internet searching capability. For that reason, Surakarta Regional Office and study groups should conduct comprehensive training on "how to search the information through the internet", so that students can realistically use the internet for searching information.

$>$ The use of social media is directed to be applied as second media for the purpose of their learning process. The students as adult people generally fond of using the social media e.g. facebook, twitter, or others to make contacts with their colleagues by means of cellular phones. By this, they can update their friends in their environments. To insert learning purposes to this "easy touch" media hopefully can overcome the limitations and cost of existing media technologies. Therefore it is necessary to develop the management information so that students can be more intense in communicating both with the tutor and other interested parties as well as obtaining information immediately.

\section{BIODATA and CONTACT ADDRESSES of the AUTHORS}

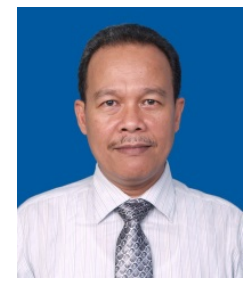

Djoko RAHARDJO was born in Surakarta, Indonesia on June 25, 1958. He graduated from Magister of Librarian and Information Study, Faculty of Humanities, University of Indonesia in 2004. When he wrote this article he was a doctoral candidate of Development Communication Study Program at Bogor Agricultural University. He is a lecturer in Communication Science Department, Universitas Terbuka Indonesia. His main interests are communication media and distance education.

Djoko Rahardjo, M. Hum

Universitas Terbuka, Indonesia

Faculty of Social and Political Science

Jalan Cabe Raya Pamulang, Tangerang Selatan, Indonesia

Email: rahardjo@ut.ac.id , dj.rahardjo@gmai.com

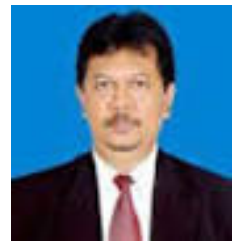

Prof. Dr. SUMARDJO was born in Sukoharjo Indonesia on February 25, 1958. He graduated from the Bogor Agricultural University, Department of Communication / Extension Development in 1999. He was professor of extension development at the Faculty of Human Ecology, Bogor Agricultural University. He graduated master of science in rural sociology Bogor Agricultural University in 1988. He serves as the head of the Research Center for Conflict Resolution and Social Empowerment. The main interest in the research is education development, cyber extension, community development, and conflict resolution.

Prof. Dr. Sumardjo

Bogor Agricultural University, Indonesia

Jalan Dramaga, Bogor Indonesia

Email: sumardjo252@gmail.com 


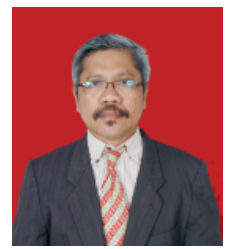

Djuara P. LUBIS was born in 1960 . He received his PhD in Development Communication from University of the Philippines, College of Development Communication in 2000. Since 1985 he has been working as lecturer in Bogor Agricultural University, Indonesia, and serves as head of Development Communication Study Program.

\section{Dr. Djuara P. Lubis}

Bogor Agricultural University, Indonesia

Jalan Dramaga, Bogor Indonesia

Email: djuaralubis@gmail.com

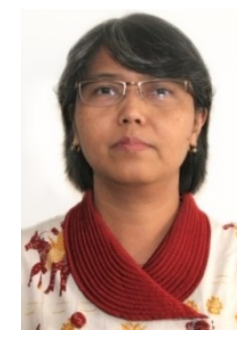

Dr. Ir. Sri HARIJATI, MA. was born in Madiun, East Java, Indonesia in 1962. She completed her doctoral program in the field of "extention of development" at Bogor Agricultural University in 2006. She works at Universitas Terbuka since 1988 on The Study Program of Agribusiness. She has been working as an online Tutor for several agricultural extension cources. Universitas Terbuka is an Indonesia university that implements open and distance education system. She is interested in areas of research in online learning.

Dr. Ir. Sri Harijati, MA.

Faculty of Mathematics and Natural Sciences, Universitas Terbuka, Indonesia

Jalan Cabe Raya, Pondok Cabe, Pamulang

Tangerang Selatan, Banten, Indonesia.

Fax: (62)021 7434691

Phone: (62)021 7490941

E-mail: harijati@ut.ac.id

\section{REFERENCES}

Bentler, P.M. and C.-P. Chou. (1987). Practical issues in structural modeling. Sociological Methods \& Research 16(1): 78-117

Bucy, EP., and Newhagen, JE. (Ed) (2004). Media access: social and psychological dimensions of new technology use. London (GB): Lawrence Erlbaum Associates, Inc.

Chen, SY. and Fu, YC. (2009) Internet use and academic achievement: gender differences in early adolescence. Adolescence, 44 (176), 797-812

Daulay, P. (2008). Analysis of the contents of an interactive discussion topics Open University student in the feature "Online UT Communications Forum". Scriptura 2, 135-149

Dogruer N, Eyyam R, and Menevis I. (2011). The use of the internet for educational purposes. Prosedia- Social and Behavioral Sciences 28, 606-611

Hoyle, RH. Editor. (1995). Structural Equation Modeling: Concepts, Issues, and applications. London(GB): Sage Publications

Kline, Rex B. (2011). Principles and practice of structural equation modeling 3rd ed. New York(US): The Guilford Press

Moore, MG, Kearsley, G. (2012). Distance Education: A system view of online learning. Edition-3. Belmont(US): Wadsworth

Omotayo, BO. (2006). A survey of Internet access and usage among undergraduates in an African University. The International Information \& Library Review, 38, 215-224 
Peou, C. and Lwin, M. (2011). Integrating the internet into Cambodian higher education: exploring students' internet uses, attitudes and academic utilization. International Journal of Emerging Technologies and Society 9 (2), 95-115

Pike, S. (2004). The use of repertory grid analysis and importance-performance analysis to identify determinant attributes of universities. Journal of marketing for higher education, 14 (2), 1-14

Rye SA, Zubaidah I. 2008. Distance education and the complexity of accessing the internet. Open Learning. 23(2), 95-102. DOI: 10,1080/02680510802051897.

Stanciu, V. and Inca, A. (2014). A critical look on the student's internet use- empirical study. Accounting and Management Information systems, 13 (4), 739-754

Williamson SN. (2007). Development of a self rating scale of self-directed learning. Nurse Researcher. 14(2), 66-83. 